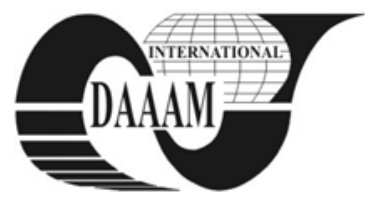

Annals of DAAAM for 2011 \& Proceedings of the 22nd International DAAAM Symposium, Volume 22, No. 1, ISSN 1726-9679 ISBN 978-3-901509-83-4, Editor B. Katalinic, Published by DAAAM International, Vienna, Austria, EU, 2011 Make Harmony between Technology and Nature, and Your Mind will Fly Free as a Bird

\title{
THERMAL EFFECTS ON STEELS AT FLAME CUTTING
}

\section{KYAS, K[amil]; STANEK, M[ichal]; MANAS, D[avid]; MANAS, M[iroslav]; OVSIK, M[artin]; SKROBAK, A[dam] \& KRUMAL, M[artin]}

\begin{abstract}
The submitted article describes the effects of a thermal separation of material on the properties of the surface layers. The separation of material is an integral part of a preparation of all final products. During cutting the surface layer of the separated material is effected, which then has an influence on the sequence of the following operations. The method of thermal separation of material was selected for the experiment described in the article a method of flame cutting. The material selected for the method was a common steel ČSN 411373, which is industrially produced and processed. The effect on the material was shown by measuring micro-hardness using the micro-hardness tester DM 2D.
\end{abstract}

Key words: micro hardness, flame cutting, vickers micro hardness

\section{INTRODUCTION}

As regards material separation methods, more sophisticated and effective methods are used today beside the classical ones. The new everyday development and changes of modern electronic technology and machine tool engineering brings new generations of many different products. Global development of these methods plays a vital role in the industrial process.

The cutting of material is usually the first operation that has to be done when producing some component. There are different types and methods of steel cutting. The most common methods of material splitting are cutting by water jet, laser, plasma and flame. In some cases, the heat caused by cutting influences the outer layers of the processed material.

Among two other common methods of cutting there are cutting by tools with defined geometry and abrasive processing - such as grinding or sanding. Some progressive methods could be also applied using physical, electrical and chemical processes as well as other sources of energy for removal of the material.

All these methods of material splitting force us to explore their impact to the qualities of cut material, especially to the layer that is in direct contact with the cutting tool. Learning about changes in structure and qualities of processed materials could assist in development of material separation and processing technologies.

\subsection{Testing of micro-hardness}

Development of hardness measurement methods for individual structural parts - measurement of micro-hardness was an important requirement for studying the structure of solids. Micro-hardness testing devices are inbuilt in metallographic microscopes or they are used as stand-alone devices.

Measurement of micro-hardness is done by pushing of the diamond body, shaped in Vickers or Knoop pyramid, into the surface of measured body by forces ranged from $1 \mathrm{~g}(0,009807$
$\mathrm{N})$ to $1000 \mathrm{~g}(9,807 \mathrm{~N})$. While common testing of (macro) hardness according to Vickers is done by means of load of $10 \mathrm{~N}$ to $1200 \mathrm{~N}$, the forces weaker than $10 \mathrm{~N}$ were used first in 1932, when such testing was done at the National Physical Laboratory in UK.

The accuracy of measurement is lower as the applied forces are weaker (smaller size of the dint). Moreover, as the load force weakens and enters the area of micro-hardness, the Vickers hardness is no more depending on the power of applied load (unlike in macro-hardness that is measured according to geometric similarity of individual dints).

\subsection{Micro-hardness according to Vickers}

Test of hardness according to Vickers is prescribed by European standard ČSN EN ISO 6507-1.

The penetrating body - made of diamond shaped as a regular tetragonal pyramid with the square base and with preset vertex angle $\left(136^{\circ}\right)$ between opposite walls - is pushed against the surface of testing body. Then, the diagonal size of the dint left after load removal is measured (Fig. 1).

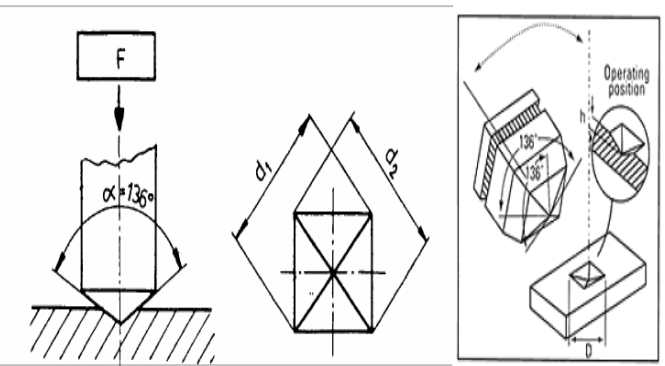

Fig. 1. The basic principle of hardness testing according to Vickers

$$
F=0,1891 \times\left(F / d^{2}\right)
$$

Where:

$\mathrm{F}$ - Testing load in $\mathrm{N}$

$\mathrm{d}$ - Arithmetic average of two diagonals d1, d2 in $\mathrm{mm}$.

Vickers' hardness is then expressed as the ratio of the testing load applied to dint area in form of regular tetragonal pyramid with square base and the vertex angle equal to the angle of penetrating body $\left(136^{\circ}\right)$.

\section{EXPERIMENTAL PART}

There was one methods of material cutting selected in the experimental part. The method has a thermal impact to the outer layer. Steel ČSN 411373 was selected for testing of thermal influence in the cutting area. The testing sample was made by using the technology of cutting by laser. The sample 
preparation was done in companies specialized to these technologies of material cutting.

2.1 Micro-hardness testing according to Vickers

A device used for micro-hardness testing is called microhardness tester.

\begin{tabular}{|l|l|l|l|}
\hline \multirow{2}{*}{$\begin{array}{l}\text { Steel } \\
\text { label }\end{array}$} & \multicolumn{4}{|l|}{ Chemical composure (\%) } \\
\cline { 2 - 4 } & $\mathrm{C}$ & $\mathrm{P}$ & $\mathrm{S}$ \\
\hline $\mathrm{C}$ CSN & 0,17 & 0,045 & 0,045 \\
11373 & & & \\
\hline
\end{tabular}

Tab. 1. Chemical composure of steel 11373

\begin{tabular}{|l|l|}
\hline Load & $\begin{array}{l}200 \mathrm{~g} \\
(\mathrm{HV} 0,2 \quad \mathrm{~F}=1,961 \mathrm{~N})\end{array}$ \\
\hline Load time & $10 \mathrm{~s}$ \\
\hline
\end{tabular}

Tab. 2. Measurement conditions

Micro-hardness testing of structural components and phases is one of the most important tools used in metallographic industry. By means of micro-hardness testing, individual structural components could be identified relatively exactly, such as lower and upper bainit, lowly and highly carbonated martenzit etc.

The measurement is done by means of digital microhardness tester DM 2D from AFFRI. Measurement conditions are stated in the Tab. III above. The tester is able to measure the hardness according to Vickers as well as according to Knoop. An inbuilt 16bit monolithic high-power microprocessor equipped by photomechanical software was used. Its power can be fully adjusted according to the needs of micro-hardness testing in new century.

\subsection{Sample preparation}

As the sample surface must have a metallic shine and the surface roughness must not excess $\mathrm{Ra} 0.2$, the sample preparation is very important step. In general, the sample could be fixed in a gripping or set into spaces and after grinding by soft grindstone, the sample has to be sanded by metallographic sand papers of different numbers so that the dint could be clearly seen.

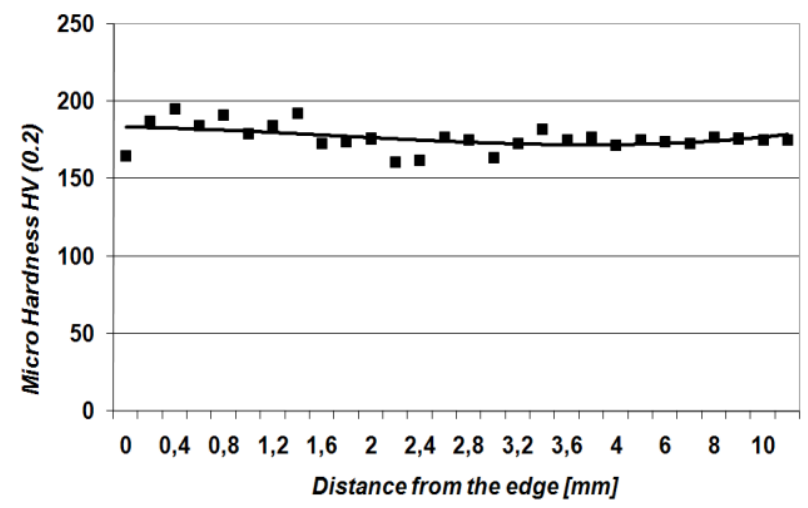

Fig. 2. Change of micro-hardness (cutting by flame)

\subsection{Flame}

The original structure of measured sample was pearlitic, respectively ferrite-pearlitic, with hardness ranging from 160 $\mathrm{HV}$ to $165 \mathrm{HV}$. Cutting by flame creates the temperature of $3000{ }^{\circ} \mathrm{C}$ with accuracy of $0,5-1 \mathrm{~mm}$. Environment temperature was $22{ }^{\circ} \mathrm{C}$. The temperature difference between the cutting area and its surrounding environment is not high enough to have an impact on nearest environment around the cutting line. The cutting is followed by cooling process on open air, thus lowering the cooling speed. This enables the creation an equilibrium state of coarse-grained pearlitic structure with globular cementite. Baling of cementite is caused by the surface tension. This change in structure causes decrease in hardness to value of $165 \mathrm{HV}$ as seen in Fig. 4.

\section{CONCLUSION}

The submitted article deals with the impact of flame cutting on the surface layer of material. The material used for experimental part was steel (ČSN - Czech state Norm) ČSN 411373. The specimen thus made were ground (polished) and in this way prepared for the microhardness test. Microhardness was measured on the microhardness tester DM - 2D. The results of the measurement were put in the graph.

The results show that testing bodies cut by laser shown the hardness of $275 \mathrm{HV}$. Maximum thickness of the layer influenced by cutting was about $2 \mathrm{~mm}$.

\section{ACKNOWLEDGEMENTS}

This article is financially supported by the internal grant of TBU in Zlín No. IGA/10/FT/11/D funded from the resources of specific university research and by the European Regional Development Fund under the project CEBIA-Tech No. CZ.1.05/2.1.00/03.0089.

\section{REFERENCES}

Oliver W.C.; G.M. Pharr.(1992) An improved technique for determining hardness and elastic modulus using load and displacement sensing indentation, J Mater Res 7 (6) pp. $1564-1583$

Krumal, M.; Stanek, M.; Manas, M.; Manas, D.; Kyas, K. \& Cerny, J. (2010). Fluidity of Thermoplastic Elastomers, $D A A A M$, p. 1185 , ISSN 1726-9679, ISBN 978-3-90150973-5, Zadar, Croatia

Manas, D., Manas, M., Stanek, M., Sanda, S., Pata, V.: Thermal effects on steel at different methods separation, 2011, Chemicke Listy 105 (17 SPEC. ISSUE), ISSN 0009-2770, pp. s713-s3716

Manas, D.; Stanek, M.; Manas, M.; Pata V. \& Javorik, J. (2009). Influence of Mechanical Properties on Wear of Heavily Stressed Rubber Parts, KGK - Kautschuk Gummi Kunststoffe, 62. Jahrgang, , ISSN 0948-3276, p.240-245

Manas, D.; Stanek, M. \& Manas, M.: (2007) Workability and Wear of Rubber Parts, Chapter 54 in DAAAM International Scientific Book 2007, Published by DAAAM International, p.611- 626, Vienna, Austria, ISBN 3-901509-60-7, ISSN 1726-9687, DOI: 10.2507/daaam.scibook.2007.54

Stanek, M.; Manas, M.; Manas, D. \& Sanda, S. (2009). Influence of Surface Roughness on Fluidity of Thermoplastics Materials, Chemicke listy, Vol 103, ISSN 0009-2770, p.91-95

G.M. Pharr.(1998) Measurement of mechanical properties by ultra-low load indentation, Mater Sci Eng A253, pp. 151159 